\author{
SERIES 'CLINICAL PHYSIOLOGY IN RESPIRATORY INTENSIVE CARE' \\ Edited by A. Rossi, C. Roussos
}

\title{
Bronchodilator delivery with metered-dose inhalers in mechanically-ventilated patients
}

\author{
R. Dhand, M.J. Tobin
}

\begin{abstract}
Bronchodilator delivery with metered-dose inhalers in mechanically-ventilated patients. R. Dhand, M.J. Tobin. (CERS Journals Ltd 1996.

ABSTRACT: Metered-dose inhalers (MDIs) provide several advantages over nebulizers, including ease of administration, decreased cost, reliability of dosing, and freedom from contamination. However, this method of aerosol delivery has been considered ineffective in mechanically-ventilated patients because most of the aerosol deposits in the endotracheal tube and ventilator circuit. A smaller amount of aerosol from a MDI is deposited in the lower respiratory tract of mechanically-ventilated patients than in ambulatory patients, although recent studies show that a significant bronchodilator effect can still be achieved. When employed optimally, significant bronchodilation occurs with as little as 4 puffs of a sympathomimetic aerosol.

Multiple factors influence the efficacy of MDIs in mechanically-ventilated patients. The method of connecting the MDI canister to the ventilator circuit has a marked effect on aerosol delivery, and other factors include the timing of MDI actuation, ventilator mode, tidal volume, circuit humidity, and duty cycle. With a proper technique of administration, a MDI serves as an effective, convenient, and safe method for delivering bronchodilator aerosols in mechanically-ventilated patients.
\end{abstract}

Eur Respir J., 1996, 9, 585-595.
Division of Pulmonary and Critical Care Medicine, Edward Hines Jr Veteran Affairs Hospital, and Loyola University of Chicago Stritch School of Medicine, Hines, IL, USA.

Correspondence: R. Dhand, Division of Pulmonary and Critical Care Medicine, 111 N, Edward Hines Jr Veterans Affairs Hospital, Hines, IL 60141, USA

Keywords: Aerosols, mechanical ventilation, nebulizers, pulmonary mechanics

Received: October 41995

Accepted December 181995

Supported by a Merit Review grant from the Department of Veteran Affairs (MJT) and a RAG grant from the Department of Veteran Affairs (RD).
Administration of therapeutic agents as aerosols provides several advantages in the treatment of pulmonary diseases. A smaller quantity of drug produces an effect comparable in magnitude to that observed with systemic administration and has a rapid onset of action [1]. The drug is delivered directly to the respiratory tract so that systemic absorption is limited and systemic sideeffects are minimized. However, the respiratory tract has a number of defence mechanisms to prevent particulate material from reaching the lower respiratory tract. To reach and deposit in the deeper portion of the lungs, particles must have a mean mass aerodynamic diameter (MMAD) of $1-5 \mu \mathrm{m}$, the so called "respirable range" [2, $3]$. Production of these micronized particles requires specialized technology. Three types of aerosol generating devices produce particles in the respirable range: metered-dose inhalers (MDIs), nebulizers and dry powder inhalers.

MDI formulation. MDIs consist of a pressurized canister containing a micronized drug powder suspended in two or more chlorofluorocarbon (CFC) propellants, together with surfactants which keep the drug particles in suspension [4]. A metering chamber fitted with an outlet valve allows discharge of multiple metered-doses from the canister. Typically, the volume of material aerosolized with each actuation in different MDI formulations varies from 25 to $100 \mu \mathrm{L}$. Newer MDIs, which contain hydrofluoroalkane (HFA) propellants, have recently been marketed. In preliminary studies, these MDIs have been shown to be as effective as conventional MDIs [5, 6].

MDIs used in mechanically-ventilated patients. In mechanically-ventilated patients, MDIs are chiefly used to deliver beta-adrenergic and anticholinergic bronchodilators for treatment of airway obstruction [7]. In the past, nebulizers were commonly employed for administration of bronchodilators in ventilator-supported patients. MDIs were considered to be ineffective [8] due to aerosol impaction in the ventilator circuit and endotracheal tube [9]. However, recent studies have clearly established the efficacy of MDI delivered bronchodilators in mechanically-ventilated patients, provided a proper technique of administration is used [10-12]. Thus, it is necessary to re-evaluate the use of MDIs in mechanically-ventilated patients.

Lower respiratory tract deposition of aerosol delivered by a MDI in mechanically-ventilated patients

In mechanically-ventilated patients, the efficiency of aerosol delivery to the lower respiratory tract depends on several factors that are not a concern in ambulatory patients (fig. 1) [7]. In particular, deposition of aerosol in the endotracheal tube and ventilator circuit causes a significant reduction in the fraction of aerosol reaching 


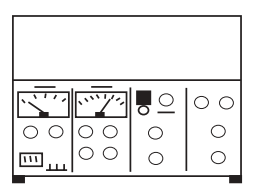

Ventilator-related

- Mode of ventilation

- Tidal volume

- Respiratory rate

- Duty cycle

- Inspiratory waveform

- Breath triggering mechanism
Drug-related

- Dose

- Timing of MDI actuation

- Aerosol particle size

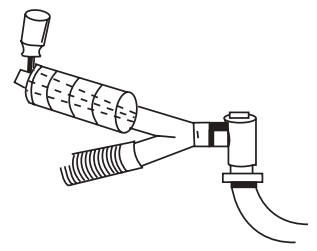

Circuit-related
Patient-related

- Severity of airway obstruction

- Mechanism of airway obstruction

- Presence of dynamic hyperinflation

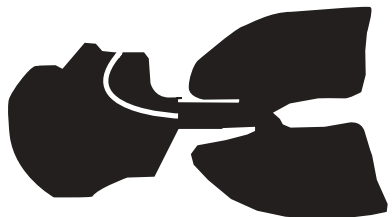

- Type of spacer or adapter used

- Position of spacer in circuit

- Endotracheal tube size

- Inhaled gas humidity

- Inhaled gas density/viscosity

Fig. 1. - Factors influencing lower respiratory tract deposition of aerosol delivered by a metered-dose inhaler (MDI) in mechanically-ventilated patients. With dry air in the circuit, $\sim 30 \%$ of the dose is delivered to the major airways if the MDI is actuated into a cylindrical spacer, whereas deposition decreases to $\sim 16 \%$ if inspired gas is humidified.

the lower respiratory tract [13-15]. When using MDIs, a special adapter is required to connect the canister to the ventilator circuit. The characteristics of the ventilatordelivered breath are quite different from a spontaneous breath. Since the response to bronchodilators using a MDI is dependent on the amount of aerosol depositing in the lower respiratory tract of ventilator-dependent patients, several investigators have studied this issue with in vivo and in vitro models.

\section{In vitro models}

Methods used to estimate aerosol deposition. Initially, aerosol deposition was assessed by collecting the output of the MDI on filters placed at the end of the endotracheal tube. Change in weight of dried filters was used to quantitate aerosol deposition [13]. Other investigators have used laser particle counts in the aerosol flume [16, 17], but this does not quantitate the absolute amount of

Table 1. - Determination of lower respiratory tract deposition of aerosol delivered by a MDI using in vitro models

\begin{tabular}{|c|c|c|c|c|}
\hline $\begin{array}{l}\text { Type of model } \\
\text { [Ref.] }\end{array}$ & Type of adapter & Breath type & Measurement & Results \\
\hline $\begin{array}{l}\text { ETT }(6.0,7.5 \text { and } \\
9.0 \mathrm{~mm}) \text { in trachea } \\
{[13]}\end{array}$ & Swivel adapter & $\begin{array}{l}\text { Continuous flow or MDI } \\
\text { actuation then flow }\end{array}$ & Filter weight & $\begin{array}{l}\text { Greater efficiency with larger } \\
\text { ETT and actuation into } \\
\text { continuous flow }\end{array}$ \\
\hline $\begin{array}{l}\text { ETT and laser } \\
\text { spectrometer [16] }\end{array}$ & $\begin{array}{l}\text { Three different } \\
\text { adapters in line or } \\
\text { cylindrical spacer }\end{array}$ & $\begin{array}{l}V \mathrm{~T} 800 \mathrm{~mL} \\
\text { flow } 60 \mathrm{~L} \cdot \mathrm{min}^{-1}\end{array}$ & $\begin{array}{l}\text { Particle volume } \\
1-5 \mu \mathrm{m}\end{array}$ & $\begin{array}{l}\text { Adapters produced lower volume } \\
\text { of particles than standard } \\
\text { actuator }\end{array}$ \\
\hline $\begin{array}{l}\text { Ventilator circuit; } \\
\text { ETT ( } 8 \mathrm{~mm}) \text { [19] }\end{array}$ & $\begin{array}{l}\text { Swivel adapter at } \\
\text { ETT or cylindrical } \\
\text { spacer }\end{array}$ & $\begin{array}{l}V \mathrm{~T} 800 \mathrm{~mL} \\
\text { flow } 48 \mathrm{~L} \cdot \mathrm{min}^{-1}\end{array}$ & Albuterol assay & $\begin{array}{l}\text { Greater deposition with } \\
\text { cylindrical spacer }\end{array}$ \\
\hline $\begin{array}{l}\text { ETT and laser } \\
\text { spectrometer [17] }\end{array}$ & $\begin{array}{l}\text { Nine different MDI } \\
\text { spacers or adapters }\end{array}$ & - & $\begin{array}{l}\text { Particle volume } \\
0.7-5.0 \mu \mathrm{m}\end{array}$ & $\begin{array}{l}\text { Chamber spacers delivered } \\
\text { greater volume than other } \\
\text { adapters }\end{array}$ \\
\hline Ventilator circuit [22] & $\begin{array}{l}\text { MDI with large } \\
\text { chamber or small } \\
\text { chamber spacer }\end{array}$ & $\begin{array}{l}V \mathrm{~T} 700 \mathrm{~mL} \\
\text { flow } 50 \mathrm{~L} \cdot \mathrm{min}^{-1}\end{array}$ & Radioactivity & Similar delivery with the devices \\
\hline $\begin{array}{l}\text { Plastic syringe and } \\
\text { simulated carina }[20]\end{array}$ & MDI with catheter & - & Albuterol assay & $\begin{array}{l}\approx 90 \% \text { of dose delivered beyond } \\
\text { ETT }\end{array}$ \\
\hline $\begin{array}{l}\text { ETT }(6 \mathrm{~mm}) \text { and } \\
\text { swivel adapter [23] }\end{array}$ & $\begin{array}{l}\text { Catheters placed in } \\
\text { ETT ( } 13 \text { or } 22 \mathrm{~cm} \\
\text { long) }\end{array}$ & Flow $30 \mathrm{~L} \cdot \mathrm{min}^{-1}$ & Albuterol assay & $\begin{array}{l}\text { Longer catheters delivered } \\
\text { greater dose than shorter } \\
\text { catheter }\end{array}$ \\
\hline $\begin{array}{l}\text { Model of trachea and } \\
\text { main bronchi [21] }\end{array}$ & Cylindrical spacer & $\begin{array}{l}\text { Flow } 40 \mathrm{~L} \cdot \mathrm{min}^{-1} \\
8 \mathrm{~mm} \mathrm{ETT}\end{array}$ & Albuterol assay & $\begin{array}{l}\text { Decreased deposition with } \\
\text { humidification and CMV breaths }\end{array}$ \\
\hline
\end{tabular}

MDI: metered-dose inhaler; ETT: endotracheal tube; $V \mathrm{~T}$ : tidal volume; CMV: controlled mechanical ventilation. 


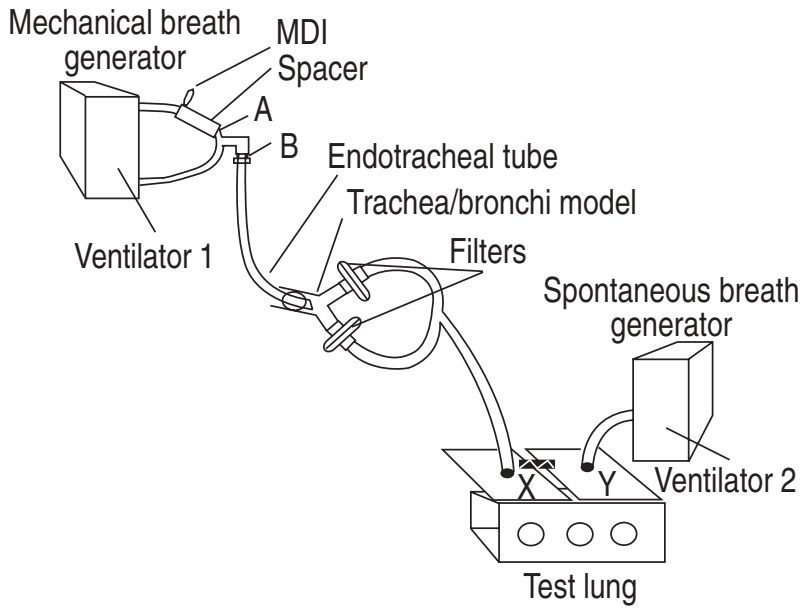

Fig. 2. - Diagram of a bench model to test aerosol deposition during mechanical ventilation. Ventilator 1 generated machine delivered breaths. The metered-dose inhaler (MDI) was actuated into a cylindrical spacer placed in the inspiratory limb of the ventilator circuit (A). The ventilator circuit was connected to an endotracheal tube with an elbow connector (B). The endotracheal tube with balloon inflated was positioned inside a model of the trachea and mainstem bronchi. The aerosol deposited on filters placed at the ends of each bronchus. Ventilator 2 was used to simulate patient respiratory effort (spontaneous breathing) by inflation of sections $\mathrm{Y}$ and $\mathrm{X}$ of the test lung.

drug being delivered. When radioactive materials are employed to assess aerosol deposition, the type of radioactive label used may influence the findings [18]. Direct assay of the active drug in the MDI formulation is a simple, inexpensive and reliable method of measuring aerosol deposition [19-21].

Types of in vitro models. Various models of the ventilator circuit have been employed to assess in vitro aerosol deposition (table 1). In most studies, aerosol was collected distal to the endotracheal tube [13, 16, 17, 22, 23]. Subsequently, Niven et al. [20] used a plastic syringe barrel with a simulated carina to quantitate aerosol deposition in the lower trachea. In our laboratory, FINK et al. [21] used a model that has the endotracheal tube placed within a plastic trachea which bifurcated into two main bronchi. The model was constructed to match the dimensions of a normal adult human airway [24]. Filters placed at the ends of the two bronchi collect drug aerosol (fig. 2). This apparatus simulates aerosol delivery to the major airways in mechanically-ventilated patients more accurately than the models used previously.

Aerosol deposition in the endotracheal tube. Aerosol produced by a MDI emerges as a jet at a high velocity and then rapidly expands into a flume [25]. As the aerosol travels through air, the propellant evaporates and MMAD of the aerosol decreases rapidly. Larger particles travelling at high velocity are lost by impaction when a MDI is connected directly to the endotracheal tube [13]. As a result, only a very small proportion of aerosol is able to cross the endotracheal tube. Obviously, the narrower the endotracheal tube the greater are the losses due to aerosol impaction [13]. Some workers have attempted to overcome this problem by attaching a long catheter to the nozzle of the MDI $[20,23]$. As the distal end of a)

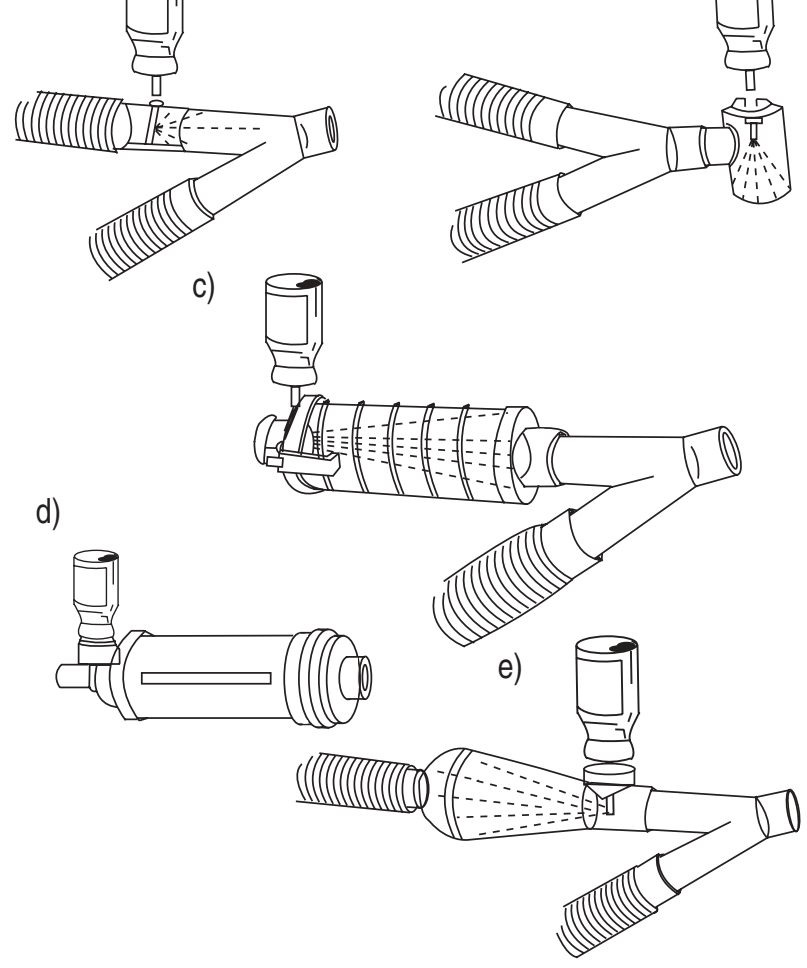

Fig. 3. - Different types of commercially available spacers/adapters used to connect the metered-dose inhaler (MDI) canister to the ventilator circuit. a) in-line adapter b) elbow adapters; c) collapsible cylindrical spacer chamber that can be fitted in the inspiratory limb of the ventilator circuit; d) noncollapsible cylindrical holding chamber; e) aerosol cloud enhancer (ACE) spacer, whereby the MDI flume is directed away from the patient.

the catheter extends beyond the endotracheal tube, most of the aerosol is delivered directly to the lower respiratory tract. With this delivery system, the fraction of aerosol in the respirable range has been determined [23]; however, the deposition pattern in vivo has not been defined, and concerns have been raised about mucosal damage induced by propellants, surfactants or other constituents of the MDI formulation [26].

Types of adapters used with MDI. Several types of commercially available adapters are used to connect the MDI canister to the ventilator circuit. These include: 1) elbow devices that connect to the endotracheal tube; 2) in-line devices that are placed in the inspiratory limb of the ventilator circuit; and 3) chamber adapters, including cylindrical spacers and reservoir devices (fig. 3). In a mechanically-ventilated lung model, RAU et al. [19] showed that the combination of a MDI and a chamber device resulted in a fourfold greater delivery of aerosol when compared with actuation of the MDI into a connector placed directly at the endotracheal tube (fig. 4). Fuller and co-workers [27] also reported that incorporation of a chamber type adapter in the inspiratory limb of the ventilator circuit significantly improved pulmonary deposition compared with a device that allows MDI actuation into the inspiratory limb but lacks a chamber (Instrumentation Industries Inc., Bethel Park, PA, USA). Use of an adapter connected directly to the endotracheal 


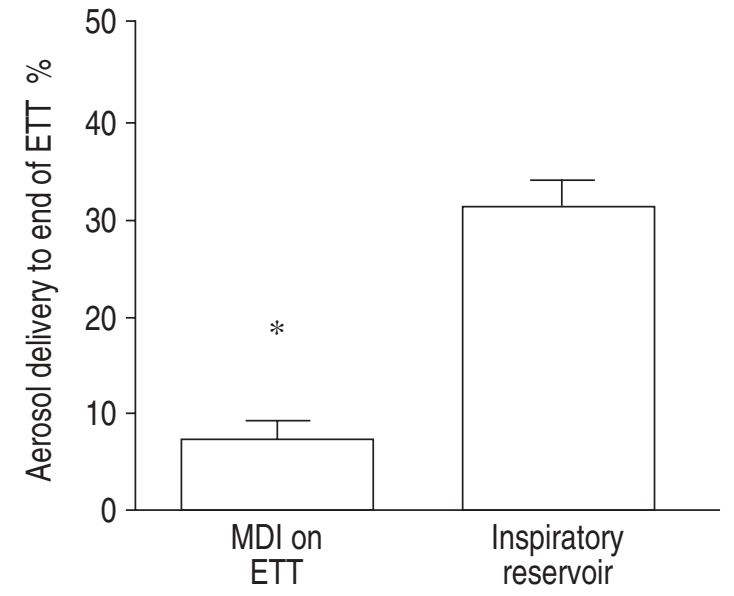

Fig. 4. - Percentage aerosol delivery at the distal end of the endotracheal tube with the metered-dose inhaler (MDI) connected to the endotracheal tube (ETT) and MDI actuation into a cylindrical chamber placed in the inspiratory limb proximal to the $\mathrm{Y}$ connector. Actuation of the MDI into a cylindrical chamber significantly improved aerosol delivery (*: p<0.01). (Modified from RAU et al. [19]. Reproduced with permission).

tube results in considerable deposition of aerosol within the tube itself, resulting in negligible therapeutic effects even after administration of very high doses from a MDI [8]. Therefore, a spacer device with a chamber placed at a distance from the endotracheal tube is the preferred method for delivery of an aerosol by MDIs in mechanically-ventilated patients.

Influence of ventilator mode and settings on aerosol deposition. In the model described by FINK et al. [21], albuterol deposition was up to $23 \%$ lower during controlled mechanical ventilation than with simulated spontaneous breaths of equivalent tidal volume (fig. 2). In nonintubated patients, quiet spontaneous breathing was associated with $32 \%$ greater deposition in the lung than aerosol delivered by intermittent positive pressure breathing with the same nebulizer [28]. Larger inspiratory time was associated with greater aerosol deposition during controlled mechanical ventilation, assist-control and pressure support modes [21]. Aerosol deposition strongly correlated with an increase in duty cycle (duration of inspiration/duration of total breathing cycle $(t \mathrm{I} / t \mathrm{TOT}))$ in all ventilator modes. During spontaneous breaths, there was a linear correlation of albuterol deposition with tidal volume, which was not present with the other modes of ventilation [21].

Effect of heat and humidification. Gas delivered to mechanically-ventilated patients must be heated and humidified to prevent drying of the airway mucosa. Heating and humidification of inhaled gas decreases aerosol deposition both with MDIs and nebulizers by about one third to one half $[21,29,30]$. The effect of humidity on the particle size and deposition of saline aerosols has been well characterized [31]. However, the effect of humidity on particle size in MDI-generated aerosols, which have a coating of surfactant and propellant, has not been systematically studied. With an oropharyngeal model, KIM et al. [32] reported that the MMAD of aerosols produced by MDIs did not increase as relative humidity of air was increased from $<1 \%$ to $90 \%$. However, the degree of relative humidity in ventilator circuits is higher $(\approx 98 \%)$ than that used by KIM et al. [32], and, thus, aerosol particle size would be expected to be 15-20\% larger than in the latter studies. Conceivably, humidification in the circuit influences the rate of evaporation of propellants, with different patterns of particle size development and subsequent variations in deposition pattern of MDI-generated aerosols.

\section{Aerosol deposition studies in vivo}

Aerosol deposition in the lower respiratory tract can be estimated by radionuclide studies or serum level estimation.

Radionuclide studies. Radionuclide studies noninvasively assess total and regional aerosol deposition in the lower respiratory tract. FULLER and co-workers [15] actuated a MDI containing fenoterol and $99 \mathrm{mTc}$-pertechnate into a cylindrical chamber placed in the inspiratory limb of a ventilator circuit. About $6 \%$ of the dose was deposited in the lower respiratory tract (fig. 5), a value significantly lower than that reported with a MDI and spacer in nonintubated ambulatory patients ( 24\%) [33]. In a subsequent study, FULLER and co-workers [27] compared the aerosol delivery to the lower respiratory tract in mechanically-ventilated patients with actuation of the MDI into different types of spacer devices. Values of pulmonary deposition with two chamber devices were similar and higher than those observed with an elbow adapter.

Several in vitro model studies of a MDI and spacer revealed about $30 \%$ delivery to the lower respiratory tract $[19,21,22]$. These values are consistently higher than pulmonary deposition estimated by in vivo gammascintigraphic studies. The difference between in vivo and in vitro data may be due to humidification in the ventilator circuit. Also, the quantity of exhaled aerosol

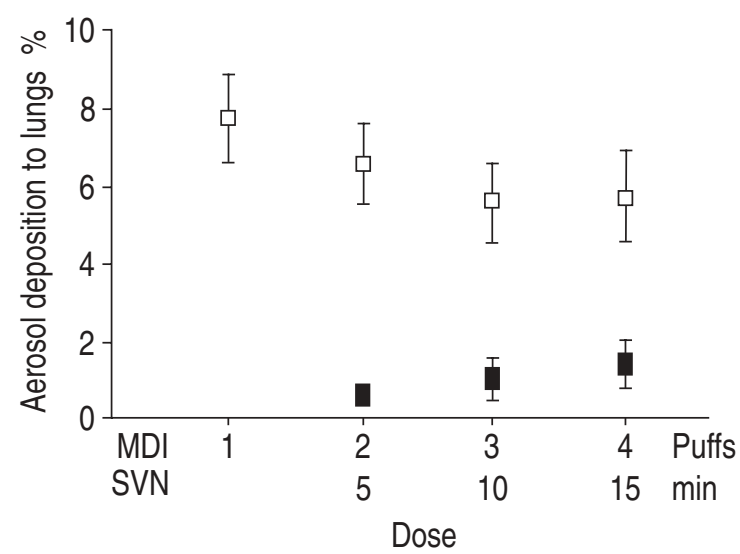

Fig. 5. - Cumulative deposition of aerosol to the lungs expressed as a percentage of the dose delivered for patients receiving radiolabelled fenoterol with a metered-dose inhaler (MDI) or small volume nebulizer (SVN). Dose expressed as number of puffs for MDI and time with SVN. With the MDI 5.65 $\pm 1.09 \%$ of the dose deposited in the lungs compared to $1.22 \pm 0.35 \%$ with the SVN. $\square$ : MDI $(n=7) ; \boldsymbol{\square}$ : SVN $(n=9)$ ). (Modified from FULLER and co-workers [15]. Reproduced with permission). 
is not included in the in vitro measurement. In a bench model, we found that $\sim 16 \%$ of the dose from a MDI was delivered to the lower respiratory tract when the ventilator circuit was humidified [21]; in our mechanically-ventilated patients, $2-3 \%$ of the aerosol was exhaled (unpublished data). Thus, in vitro studies indicate that $13-14 \%$ of the dose from a MDI is deposited in the lower respiratory tract when using a humidified ventilator circuit, which is greater than the value of $\sim 6 \%$ found in the in vivo studies of FULLER and co-workers [15]. However, the latter in vivo studies did not account for tissue quenching of radioactivity [27]. When a correction is made for this factor, deposition in the lower respiratory tract is approximately twice that initially reported by FULLER and co-workers [15], i.e. 11-12\%. Allowing for minor differences in methodology, data obtained with humidified ventilator circuits in vitro are comparable with those obtained by radionuclide studies in vivo when a correction is made for quenching of radioactivity by the tissues of the chest wall.

Estimation of serum levels. In mechanically-ventilated patients, unlike nonintubated patients, direct deposition of aerosol in the oropharynx and subsequent enteral absorption cannot occur. Therefore, estimation of serum levels of drugs administered by a MDI should reflect lower respiratory tract deposition. Sensitive assays are required to measure the very low levels of drug in serum [34]. Preliminary findings suggest that administration of albuterol with a MDI and spacer produces peak serum levels which are similar to those in healthy controls [35], although the area under the concentration time curve is lower in mechanically-ventilated patients than in healthy normal controls. These findings support earlier radionuclide studies, which suggested that lower respiratory tract aerosol deposition is decreased in ventilator-supported patients.

\section{Efficacy of bronchodilator administered by a MDI in mechanically-ventilated patients}

Selection of patients. Bronchodilator therapy is commonly used in the Intensive Care Unit [36], although the indications for its use are not well-defined. Patients with chronic obstructive pulmonary disease (COPD) demonstrate a significant decrease in airway resistance after administration of bronchodilators with a MDI (fig. $6)[11,12]$. Similarly, patients with the adult respiratory distress syndrome (ARDS) showed decrease in airway resistance with nebulized metaproterenol [37]. The presence of airway reactivity in patients with ARDS is somewhat surprising and emphasizes the need for further studies to establish the indications for bronchodilator therapy in mechanically-ventilated patients.

Variable efficacy of bronchodilators delivered by a MDI in mechanically-ventilated patients. Few investigators have examined the efficacy of bronchodilators in mechanically-ventilated patients [8, 11, 12, 15, 38-44]. Early studies showed promising results following bronchodilator administration by a MDI [42-44], and yet the data were
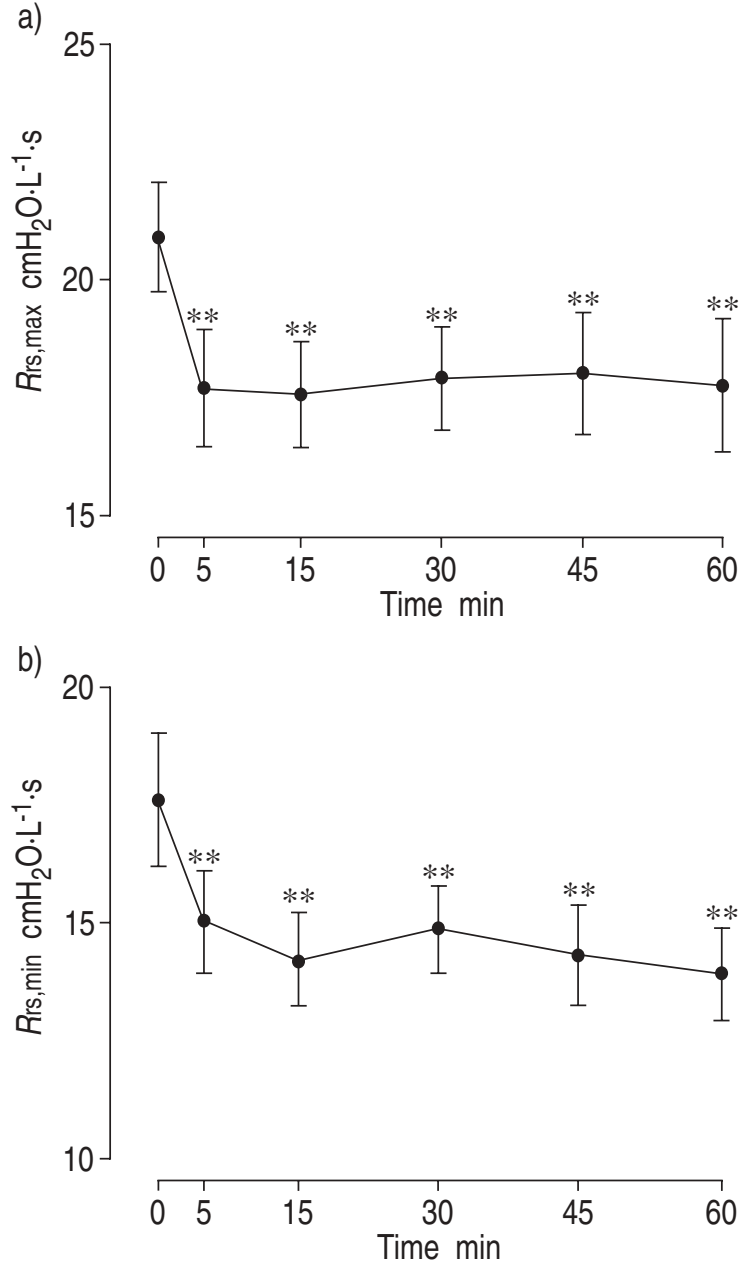

Fig. 6. - Effect of albuterol administration with a metered-dose inhaler (MDI) and cylindrical spacer on: a) maximal inspiratory resistance $(R r s, \max )$ and; b) minimal inspiratory resistance $(R \mathrm{rs}, \mathrm{min})$ in seven patients with chronic obstructive pulmonary disease (COPD). Significant decreases in $R \mathrm{rs}$, max and $R \mathrm{rs}$, min were observed $5 \mathrm{~min}$ after albuterol administration, which were sustained for $60 \mathrm{~min}$ ( $\mathrm{p}<0.01$ compared to baseline). Bars represent SEM. **: $\mathrm{p}<0.01$ from zero time. (From DHAND et al. [11]. Reproduced with permission).

ignored for several years. During that hiatus, adapters to connect a MDI to the ventilator circuit became commercially available. In subsequent studies, different dosages of bronchodilators and different techniques of administration were used to evaluate the efficacy of MDIs in mechanically-ventilated patients (table 2). A significant response to bronchodilators was demonstrated in most studies in which the MDI was actuated into a cylindrical spacer or a short catheter connected to the MDI nozzle was placed in the endotracheal tube. In view of the many variables that can influence aerosol deposition, an optimal technique of administration is essential to obtain a response to bronchodilators in mechanicallyventilated patients (table 3 ).

Assessment of the bronchodilator response. The assessment of the bronchodilator response can present complex and unique problems in mechanically-ventilated patients. Since a forced expiratory manoeuvre is not usually possible, the forced vital capacity (FVC) or forced expiratory 
Table 2. - Technique of administration and response to bronchodilator delivered by MDI in mechanically-ventilated patients

\begin{tabular}{|c|c|c|c|}
\hline Authors [Ref.] & Drug/dose & Inflation & Results \\
\hline GAY et al. [38] & Albuterol $(0.3 \mathrm{mg})^{\$}$ & Manual with breathhold & $\begin{array}{l}\text { Increase in expiratory flow not } \\
\text { significant }\end{array}$ \\
\hline FERNANDEZ et al. [39] & $\begin{array}{l}\text { Albuterol }(0.2 \mathrm{mg}) \text { or } \\
\text { ipratropium }(0.04 \mathrm{mg})^{\#}\end{array}$ & Manual with breathhold & Significant decrease in $P$ peak, PEEPi \\
\hline FULLER et al. [15] & Fenoterol $(0.8 \mathrm{mg})^{\ddagger}$ & Ventilator breaths & Decrease in $P$ peak not significant \\
\hline MANCEBO et al. [40] & Albuterol $(1.0 \mathrm{mg})^{\ddagger}$ & Spontaneous breaths & Significant decrease in $R$ aw \\
\hline Manthous et al. [8] & Albuterol $(10.0 \mathrm{mg})^{\$}$ & Ventilator breaths & No change in $R$ aw \\
\hline FERNANDEZ et al. [41] & $\begin{array}{l}\text { Ipratropium }(0.04 \mathrm{mg}) \\
\text { /ipratropium + fenoterol }(0.1 \mathrm{mg})^{\#}\end{array}$ & Manual with breathhold & $\begin{array}{l}\text { No change in } R \text { aw with ipratropium; } \\
\text { significant decrease in } R \text { aw with } \\
\text { combination }\end{array}$ \\
\hline DHAND et al. [11] & Albuterol $(1.0 \mathrm{mg})^{\ddagger}$ & Ventilator breaths & Significant decrease in $R$ aw \\
\hline Manthous et al. [10] & Albuterol $(0.5,1.5,3.0 \mathrm{mg})^{\ddagger}$ & Ventilator breaths & $\begin{array}{l}\text { Significant decrease in Raw with } 15 \text { or } \\
30 \text { puffs }\end{array}$ \\
\hline DHAND et al. [12] & Albuterol $(0.4,1.2,2.8 \mathrm{mg})^{\ddagger}$ & Ventilator breaths & $\begin{array}{l}\text { Significant decrease in } R \text { aw with } 4,12 \\
\text { or } 28 \text { puffs }\end{array}$ \\
\hline
\end{tabular}

ETT: endotracheal tube; $P$ peak: peak airway pressure; PEEPi: intrinsic positive end-expiratory pressure; $R$ aw: airway resistance; $\$$ : MDI actuated into adapter connected to ETT; \#: MDI actuated into adapter with short catheter into ETT; $¥$ : MDI actuated into spacer.

Table 3. - Technique of administration of a metereddose inhaler (MDI) in mechanically-ventilated patients

1. Use spontaneous breathing if $V \mathrm{~T}>500 \mathrm{~mL}$

2. Assure $V \mathrm{~T}>500 \mathrm{~mL}$ (in adults) if breathing is assisted by ventilator

3. Use duty cycle $>0.3$, if possible

4. Shake the MDI vigorously

5. Place canister in actuator of a cylindrical spacer situated in inspiratory limb of ventilator circuit

6. Actuate MDI immediately before inspiratory flow by the ventilator

7. Allow a breathhold at end-inspiration for 3-5 s\#

8. Allow passive exhalation

9. Repeat actuations after $20-30 \mathrm{~s}$ until total dose is delivered

\#: the effects of a postinspiratory breathhold have not been evaluated in mechanically-ventilated patients; $\uparrow:$ the manufacturer recommends repeating the dose after $1 \mathrm{~min}$; however, 20-30 s interval between doses is a time-saving technique that does not compromise the drug delivery by a MDI [45]. VT: tidal volume.

volume in one second (FEV1) cannot be determined in mechanically-ventilated patients. Thus, other indices have to be used to assess response to bronchodilators, such as: 1) reduction in airway resistance; 2) increase in expiratory flow rates; 3 ) reduction in the degree of hyperinflation; and 4) reduction in the work of breathing.

Reduction of airway resistance. Inspiratory resistance can be readily measured in mechanically-ventilated patients, whereas the measurement of expiratory resistance is complicated by the presence of flow limitation (see below).
Several different methods have been used to measure inspiratory airway resistance $[46,47]$. The rapid airway occlusion at constant flow inflation technique has been employed to assess response to bronchodilators in mechanically-ventilated patients [48]. This technique, which bas been extensively investigated by workers at the Meakins-Christie laboratories in Montreal, is readily applicable to modern ventilators having a constant inspiratory flow [49]. This method has been commonly used to characterize the bronchodilator response in mechanically-ventilated patients [8, 10-12, 39, 41, 50].

To measure inspiratory airway resistance in a passively-ventilated patient, rapid airway occlusion is performed at the end of inspiration delivered with a constant airflow. The airway occlusion produces an immediate drop in peak airway pressure $(P$ peak $)$ to a lower initial pressure $(P$ init) (fig. 7$)$. The pressure then declines gradually to reach a plateau after $3-5 \mathrm{~s}$ (Pplat). The value of $P$ init can be determined by curvilinear back extrapolation of the slope of the latter part of the airway pressure tracing to the time of airway occlusion [51-53]. This permits inspiratory resistance to be partitioned into a minimal inspiratory resistance $(R \mathrm{rs}, \mathrm{min})$, which reflects the "ohmic" resistance of the airways and the total or maximal inspiratory resistance $(R \mathrm{rs}, \max )$. The latter includes $R$ rs,min and contribution by an additional effective resistance $(\Delta R \mathrm{rs}) . \Delta R \mathrm{rs}$ represents two phenomena: time constant inhomogeneities within the lung ("pendelluft"); and the viscoelastic behaviour or stress relaxation of the pulmonary tissues [52]. Similarly, airway occlusion at end-exhalation produces an increase in airway pressure, and its plateau value signifies the level of intrinsic positive end-expiratory pressure (PEEPi) [54] (fig. 7). From these measurements in a passively-ventilated 
a)
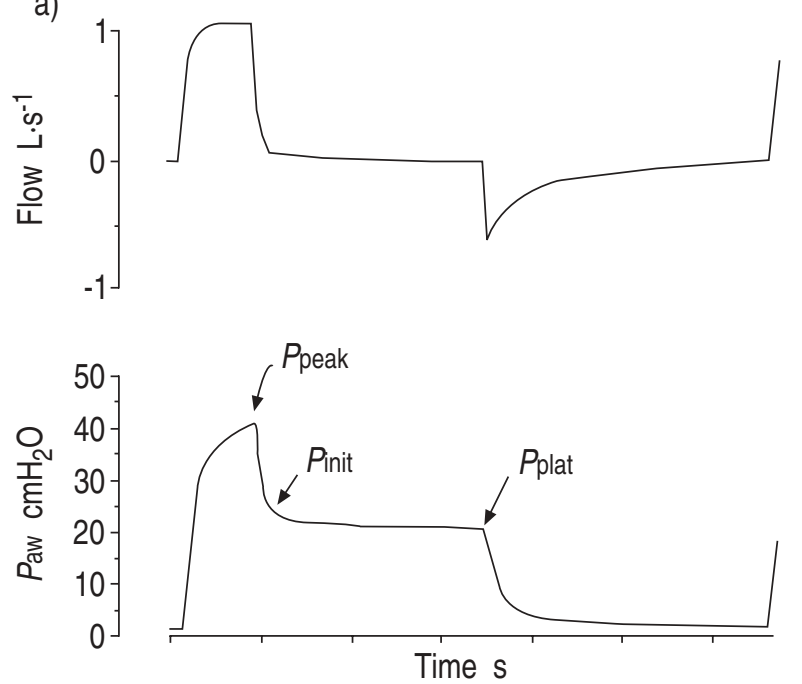
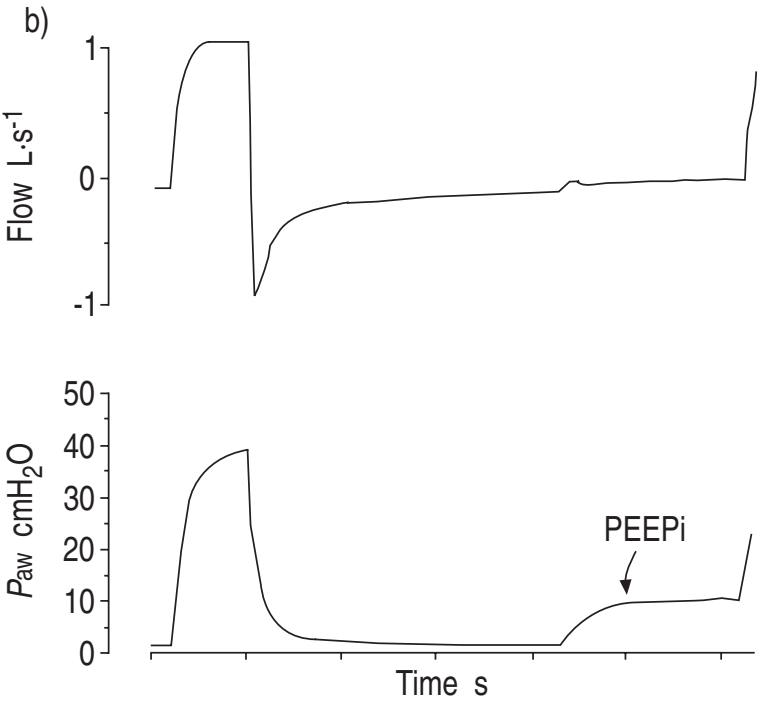

Fig. 7. - Recording of airflow and airway pressure $(P$ aw $)$ from a mechanically-ventilated patient with chronic obstructive pulmonary disease (COPD) showing effect of rapid airway occlusion at: a) end-inhalation and; b) end-exhalation. An end-inspiratory occlusion produced a rapid decline from peak pressure $(P$ peak $)$ to a lower initial pressure $(P$ init $)$, followed by a gradual decline to a plateau pressure $(P$ plat $)$. Occlusion of the airway at end-exhalation produced an increase in airway pressure, and its plateau value signifies the level of intrinsic positive end expiratory pressure (PEEPi). (From Dhand et al. [11]. Reproduced with permission).

patient, respiratory mechanics can be calculated as:

$$
\begin{aligned}
R \text { rs,max } & =\frac{\left[P_{\text {peak }}-P_{\text {plat }}\right]}{\text { airflow }} \\
R_{\text {rs,min }} & =\frac{\left[P \text { init }-P_{\text {plat }}\right]}{\text { airflow }} \\
\Delta R \text { rs } & =R \text { rs,max }-R \text { rs,min }
\end{aligned}
$$

Respiratory system compliance $(C$ rs $)=$ tidal volume

$$
\overline{[P \text { plat }- \text { PEEPi }]}
$$

A decrease in values of $R$ rs, max and $R$ rs, min occurs following bronchodilator administration in mechanicallyventilated patients $[11,12,39,41,50]$.

In mechanically-ventilated patients, only one group of investigators have examined changes in expiratory resistance following bronchodilator administration. In a randomized trial, GAY et al. [38] compared the efficacy of three puffs of albuterol with $2.5 \mathrm{mg}$ of nebulized albuterol. Expiratory resistance was measured by using stepwise deflations at lung volumes between end-inspiration and static equilibrium volume. The relationship between airway occlusion pressures (elastic recoil pressure) and expiratory flows in the mid vital capacity range, i.e. between recoil pressures of 6 and $10 \mathrm{cmH}_{2} \mathrm{O}$, was linear. Airflows at these recoil pressures were determined from these linear approximations (fig. 8). However, in patients with COPD who have dynamic airway collapse during tidal breathing, expiratory decay of alveolar pressure is multiphasic and cannot be modelled on the basis of a single compartment model. Moreover, in patients with flow limitation and dynamic hyperinflation, once the driving pressure exceeds a critical value, expiratory flow remains constant. Thus, expiratory resistance measured by this technique of stepwise deflations would overestimate the

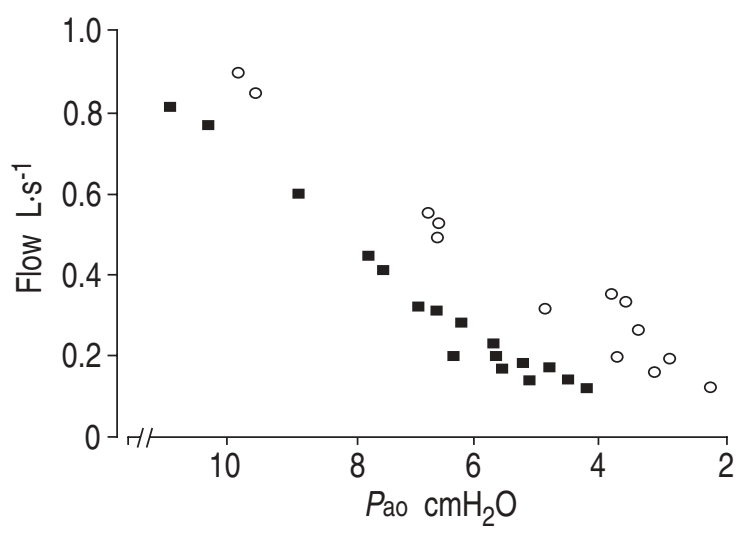

Fig. 8. - Representative pressure/flow curves constructed from data points obtained by repetitive interruption of airway during relaxed deflation. The squares represent the expiratory flow/recoil pressure relationship prior to bronchodilator therapy. The circles were derived from deflation manoeuvres following three puffs of albuterol with a metered-dose inhaler (MDI). Flow increased at all recoil pressures consistent with a fall in the expiratory resistance of the respiratory system. Pao: airway opening (mouth) pressure. (Modified from GAY et al. [38]. Reproduced with permission).

true resistance [55]. In addition, small increases in expiratory isovolume flow result in a significant shift in lung volume in these hyperinflated patients and a decrease in PEEPi [56]. For these reasons, the expiratory resistance measured by the airway occlusion technique has not been widely applied for assessment of the bronchodilator response in mechanically-ventilated patients.

Increase in expiratory flow. An increase in measured expiratory flow rates is a commonly used indicator of bronchodilator responsiveness in ambulatory patients. In relaxed, passively-ventilated patients, mean expiratory flow, i.e. the ratio of tidal volume to expiratory time, is determined solely by the ventilator settings. With 
constant ventilator settings, decrease in expiratory resistance is not accompanied by an increase in mean expiratory flow [56]. Therefore, mean expiratory flow is a poor indicator of response to bronchodilators in mechanically-ventilated patients.

A timed analysis of the expiratory flow tracing has been suggested as a method of analysing expiratory flows in mechanically-ventilated patients [57]. However, as stated above, patients with COPD have a multiphasic decay in expiratory flows. This fact, coupled with the flow limitation in these patients, makes it difficult to determine change in expiratory resistance following bronchodilator administration in ventilator-supported patients with COPD.

Reduction in hyperinflation. In patients with exacerbations of COPD or severe asthma, decrease in expiratory flow rates prevent complete exhalation before the next ventilator breath. Thus, even with low ventilator rates and prolonged expiratory time these patients are at risk of developing gas trapping. As a result, the lung volume at end-expiration remains higher than functional residual capacity. The volume of trapped gas can be measured with a spirometer by allowing exhalation of sufficient duration until all airflow ceases [58]. BERNASCONI et al. [50] showed that administration of fenoterol by a nebulizer reduced end-expiratory lung volume in patients with COPD undergoing mechanical ventilation for respiratory failure. However, measurement of trapped volume requires pharmacological paralysis of the patient and cannot be readily measured on a standard mechanical ventilator. In nonintubated patients, bronchodilator therapy often produces an increase in FVC without increase in FEV1. It would be interesting to compare the frequency of a volume response without concomitant decrease in airway resistance following bronchodilator therapy in mechanically-ventilated patients.

In patients with dynamic hyperinflation, a decrease in airway resistance must be accompanied by a decrease in lung volume and a decrease in airway pressure throughout mechanical ventilation, since inspiratory flow is constant and mean expiratory flow does not change. Therefore, a decrease in expiratory resistance should be accompanied by a decrease in PEEPi. However, a decrease in PEEPi has not been uniformly demonstrated after bronchodilator administration in mechanically-ventilated patients, probably because other factors, such as minute volume and expiratory time, influence the level of PEEPi [11, 12, 39, 50]. In addition, LEATHERMAN et al. [59] suggested that measurement of PEEPi by airway occlusion may underestimate the degree of dynamic hyperinflation. Patients with severe asthma, who showed signs of severe hyperinflation during mechanical ventilation, had low levels of measured PEEPi. Presumably, some airways may have been completely occluded in these patients and pressure in the trapped regions will not be measured by the airway occlusion method [59]. Hence, PEEPi, as measured by the airway occlusion method, may not decrease in response to bronchodilator administration in mechanically-ventilated patients with severe airways obstruction.
Reduction in the work of breathing. Inspiratory work of breathing was found to decrease in 9 out of 10 mechanically-ventilated patients following nebulization of $1.8 \mathrm{mg}$ of metaproterenol [56]. This reduction may help in weaning problem patients from mechanical ventilation [40]. In 15 intubated patients, MANCEBO et al. [40] found a significant reduction in inspiratory work of breathing after administration of 10 puffs of albuterol with a MDI and spacer. This decrease was largely due to a marked reduction in lung and airway resistance.

\section{Toxicity of drugs administered with a MDI in mechanically-ventilated patients}

Higher doses of beta-agonists delivered by a MDI may cause adverse effects because of the systemic absorption of the drug or propellants. The potential for atrial and ventricular arrhythmias must be borne in mind when high doses of beta-agonists are given in critically ill patients $[60,61]$. Although most studies have reported no adverse effects following administration of albuterol with a MDI to mechanically-ventilated patients $[8,10$, $11,38-41]$, we observed a dose-dependent increase in heart rate, becoming significant after administration of a cumulative dose of 28 puffs [12]. CFCs, used as propellants in a MDI, have a short half-life $(<40 \mathrm{~s})$ in blood after administration of a MDI to healthy volunteers. Although CFCs could sensitize the myocardium to the arrhythmogenic effects of catecholamines, depress myocardial contractility, and alter impulse conduction in experimental animals, the necessary concentrations would be achieved in patients only by inhaling from a canister with every breath for approximately 20 successive breaths [62].

A few anecdotal reports have described cardiotoxicity due to CFCs but this is unlikely to occur with the doses recommended in clinical practice, particularly if a short interval is allowed between successive doses [63]. However, administration of drugs by a MDI with a long catheter positioned in the endotracheal tube could lead to deposition of much larger quantities of surfactant and CFCs on the tracheobronchial mucosa, and systemic absorption of CFCs in concentrations sufficient to cause toxicity is distinctly possible. With this type of delivery system, SPAHR-SCHOPFER et al. [26] showed that administration of 20 puffs from a Ventolin MDI (Ventolin; Glaxo Wellcome Inc., Research Triangle Park, NC, USA), which contains oleic acid as a surfactant, produced necrotizing inflammation and ulceration in the trachea, mainstem bronchi and small bronchi of mechanically-ventilated rabbits. A placebo aerosol, containing all the ingredients in Ventolin except albuterol, also produced similar lesions, thereby indicating that epithelial injury was most likely to be due to oleic acid in the MDI formulation. Similar histological changes in the trachea and bronchi were also observed after administration of only five puffs from a Ventolin MDI [26]. Therefore, routine use of catheters as nozzle extensions to deliver drugs by a MDI past the endotracheal tube should be discouraged until the issues described above have been resolved. When 
beta-agonists are administered in higher doses, a decrease in serum potassium levels should be anticipated [64], and the possibility of paradoxical bronchoconstriction following administration of ipratropium bromide should also be considered [65].

\section{Cost of bronchodilator therapy}

The cost of bronchodilator therapy is a significant factor influencing the type of aerosol generating device used in mechanically-ventilated patients. Use of MDIs for bronchodilator therapy instead of nebulizers results in substantial cost savings [66]. BowTON et al. [67] found that substitution of nebulizers by MDIs in a 700 bed hospital could decrease potential patient costs of aerosol therapy by $\$ 300,000$ a year. In addition, MDIs offer other advantages, such as ease of administration involving less personnel time, reliability of dosing, and freedom from contamination $[68,69]$.

In conclusion, the administration of inhaled drugs to mechanically-ventilated patients is complicated by deposition of the aerosol particles in the ventilator circuit and endotracheal tube. Thus, aerosol deposition in the lower respiratory tract of mechanically-ventilated patients is lower than that in ambulatory patients. We have shown that four puffs of albuterol with a MDI and spacer produce significant bronchodilation in the majority of patients with COPD, and additive bronchodilation with higher doses is minimal [12]. The magnitude of the bronchodilator effect obtained with four puffs of albuterol $(0.4$ $\mathrm{mg}$ ) is comparable to that obtained with $2.5 \mathrm{or} 5 \mathrm{mg}$ of the drug given by a nebulizer. An optimal technique of administration requires attention to several variables; including use of a spacer, timing of MDI actuation, ventilator mode, tidal volume, circuit humidification and duty cycle. In mechanically-ventilated patients, MDIs offer several advantages over nebulizers for routine bronchodilator therapy, including the likelihood of substantial cost-savings.

Acknowledgements: The authors thank N.J. Gross for carefully reviewing the manuscript, and J.B. Fink for help with the illustrations.

\section{References}

1. Newhouse MT, Dolovich MB. Control of asthma by aerosols. N Engl J Med 1986; 315: 870-874.

2. Task Group on Lung Dynamics. Deposition and retention models for internal dosimetry of the human respiratory tract. Health Phys 1966; 12: 173-207.

3. Brain JD, Valberg PA. Deposition of aerosol in the respiratory tract. Am Rev Respir Dis 1979; 120: 1325-1373.

4. Moren F. Aerosol dosage forms and formulations. In: Moren F, Dolovich MB, Newhouse MT, Newman SP, eds. Aerosols in Medicine. 2nd revised edition. Amsterdam, Elsevier, 1993; pp. 321-350.

5. Smith DL, Aikman SL, Coulby LJ, Sutcliffe J, O'Connor BJ. The attenuation of methacholine-induced bronchoconstriction by salmeterol: comparison between an alternative metered-dose inhaler propellant GR 106642X and chlorofluorocarbons 11 and 12. Eur Respir J 1994; 7 (Suppl. 18): 318S.

6. Bleecker ER, Klinger NM, Ekholm BP, Tinkelman DG. Twelve week efficacy and safety comparison of salbutamol formulated with HFA-134a and standard CFC metered-dose inhaler devices. Am J Respir Crit Care Med 1995; 151: A58.

7. Gross NJ, Jenne JW, Hess D. Bronchodilator therapy. In: Tobin MJ, ed. Principles and Practice of Mechanical Ventilation. New York, McGraw Hill, 1994; pp. 10771123.

8. Manthous CA, Hall JB, Schmidt GA, Wood LDH. Metereddose inhaler versus nebulized albuterol in mechanicallyventilated patients. Am Rev Respir Dis 1993; 148: $1567-1570$.

9. Newhouse MT, Fuller HD. Rose is a rose is a rose? Aerosol therapy in ventilated patients: nebulizers versus metered-dose inhalers - a continuing controversy (Editorial). Am Rev Respir Dis 1993; 148: 1444-1446.

10. Manthous CA, Chatila W, Schmidt GA, Hall JB. Treatment of bronchospasm by metered-dose inhaler albuterol in mechanically-ventilated patients. Chest 1995; 107: 210213.

11. Dhand R, Jubran A, Tobin MJ. Bronchodilator delivery by metered-dose inhaler in ventilator-supported patients. Am J Respir Crit Care Med 1995; 151: 1827-1833.

12. Dhand R, Duarte AG, Jubran A, et al. Dose response to bronchodilator delivered by metered-dose inhaler in ventilator-supported patients. Am J Respir Crit Care Med (in press).

13. Crogan SJ, Bishop MJ. Delivery efficiency of metereddose aerosols given via endotracheal tubes. Anesthesiology 1989; 70: 1008-1010.

14. MacIntyre NR, Silver RM, Miller CW, Schuler F, Coleman ER. Aerosol delivery in intubated, mechanically-ventilated patients. Crit Care Med 1985; 13: 81-84.

15. Fuller HD, Dolovich MB, Posmituck G, Wong Pack W, Newhouse MT. Pressurized aerosol versus jet aerosol delivery to mechanically-ventilated patients: comparison of dose to the lungs. Am Rev Respir Dis 1990; 141: 440-444.

16. Bishop MJ, Larson RP, Buschman DL. Metered-dose inhaler aerosol characteristics are affected by the endotracheal tube actuator/adapter used. Anesthesiology 1990; 73: $1263-1265$.

17. Ebert J, Adams AB, Green-Eide B. An evaluation of MDI spacers and adapters: their effect on the respirable volume of medication. Respir Care 1992; 37: 862-868.

18. O'Riordan TG, Greco MJ, Perry RJ, Smaldone GC. Nebulizer function during mechanical ventilation. Am Rev Respir Dis 1992; 145: 1117-1122.

19. Rau JL, Harwood RJ, Groff JL. Evaluation of a reservoir device for metered-dose bronchodilator delivery to intubated adults: an in vitro study. Chest 1992; 102: 924-930.

20. Niven RW, Kacmarek RM, Brain JD, Peterfreund RA. Small bore nozzle extensions to improve the delivery efficiency of drugs from metered-dose inhalers: laboratory evaluation. Am Rev Respir Dis 1993; 147: 1590-1594.

21. Fink JB, Dhand R, Duarte AG, Jenne JW, Tobin MJ. Deposition of aerosol from metered-dose inhaler during mechanical ventilation: an in vitro model. Am J Respir Crit Care Med (in press).

22. Fuller HD, Dolovich MB, Chambers C, Newhouse MT. Aerosol delivery during mechanical ventilation: a predictive in vitro lung model. J Aerosol Med 1992; 5: 251-259. 
23. Taylor RH, Lerman J, Chambers C, Dolovich M. Dosing efficiency and particle size characteristics of pressurized metered-dose inhaler aerosols in narrow catheters. Chest 1993; 103: 920-924.

24. Horsefield K, Cumming G. Morphology of the bronchial tree in man. J Appl Physiol 1968; 34: 373-383.

25. Dhand R, Malik SK, Balakrishan M, Verma SR. High speed photographic analysis of aerosols produced by metered-dose inhalers. J Pharm Pharmacol 1988; 40: 429-430.

26. Spahr-Schopfer IA, Lerman J, Cutz E, Newhouse MT, Dolovich M. Proximate delivery of a large experimental dose from salbutamol MDI induces epithelial airway lesions in intubated rabbits. Am J Respir Crit Care Med 1994; 150: 790-794.

27. Fuller HD, Dolovich MB, Turpie FH, Newhouse MT. Efficiency of bronchodilator aerosol delivery to the lungs from the metered-dose inhaler in mechanically-ventilated patients: a study comparing four different actuator devices. Chest 1994; 105: 214-218.

28. Dolovich MB, Killian D, Wolff RK, Obminski G, Newhouse MT. Pulmonary aerosol deposition in chronic bronchitis: intermittent positive pressure breathing versus quiet breathing. Am Rev Respir Dis 1977; 115: 397-402.

29. Garner SS, Wiest DB, Bradley JW. Albuterol delivery by metered-dose inhaler with a pediatric mechanical ventilatory circuit model. Pharmacotherapy 1994; 14: 210-214

30. O'Riordan TG, Palmer LB, Smaldone GC. Aerosol deposition in mechanically-ventilated patients: optimizing nebulizer delivery. Am J Respir Crit Care Med 1994; 149: 214-219.

31. Ferron GA, Karg E, Peter J. Estimation of deposition of polydisperse hygroscopic aerosols in the human respiratory tract. J Aerosol Sci 1993; 24: 655-670.

32. Kim CS, Trujillo D, Sackner MA. Size aspects of metereddose inhaler aerosols. Am Rev Respir Dis 1985; 132: $137-142$.

33. Newman SP. Therapeutic aerosol deposition in man. In: Moren F, Dolovich MB, Newhouse MT, Newman SP, eds. Aerosols in Medicine. 2nd revised edition. Amsterdam, Elsevier, 1993; pp. 375-399.

34. Gupta RN, Fuller HD, Dolovich MB. Optimization of a column liquid chromatographic procedure for the determination of plasma salbutamol concentration. J Chromatography B Biomed Appl 1994; 654: 205-211.

35. Duarte A, Dhand R, Reid R, Tobin MJ, Jenne JW. Serum albuterol levels after metered-dose inhaler administration to ventilated patients and healthy controls. Am J Respir Crit Care Med 1995; 151: A430.

36. Boucher BA, Kuhl DA, Coffey BC, Fabian TC. Drug use in a trauma intensive care unit. Am J Hosp Pharm 1990; 47: 805-810.

37. Wright PE, Carmichael LC, Bernard GR. Effect of bronchodilators on lung mechanics in the acute respiratory distress syndrome (ARDS). Chest 1994; 106: 1517-1523.

38. Gay PC, Patel HG, Nelson SB, Gilles B, Hubmayr RD. Metered-dose inhalers for bronchodilator delivery in intubated, mechanically-ventilated patients. Chest 1991; 99: 66-71.

39. Fernandez A, Lazaro A, Garcia A, Aragon C, Cerda E. Bronchodilators in patients with chronic obstructive pulmonary disease on mechanical ventilation: utilization of metered-dose inhalers. Am Rev Respir Dis 1990; 141: 164-168.

40. Mancebo J, Amaro P, Lorino H, Lemaire F, Harf A, Brochard L. Effects of albuterol inhalation on the work of breathing during weaning from mechanical ventilation. Am Rev Respir Dis 1991; 144: 95-100.

41. Fernandez A, Munoz J, de la Calle B, et al. Comparison of one versus two bronchodilators in ventilated COPD patients. Intensive Care Med 1994; 20: 199-202.

42. Fresoli RP, Smith RM, Young JA, Gotshall SC. Use of aerosol isoproterenol in an anesthesia circuit. Anesth Analg 1968; 47: 127-132.

43. Gold MI. Treatment of bronchospasm during anesthesia. Anesth Analg 1975; 54: 783-786.

44. Wegener T, Wretman S, Sandhagen B, Nystrom S-O. Effect of ipratropium bromide aerosol on respiratory function in patients under ventilator treatment. Acta Anesthesiol Scand 1987; 31: 652-654.

45. Shalansky KF, Htan EYF, Lyster DM, Mouat B, Tweeddale MG. In vitro evaluation of the effect of metered-dose inhaler administration technique on aerosolized drug delivery. Pharmacotherapy 1993; 13: 233-238.

46. Bergman NA, Waltemath CL. A comparison of some methods for measuring total respiratory resistance. $J$ Appl Physiol 1974; 36: 131-134.

47. Tobin MJ, Van de Graaff WB. Monitoring of lung mechanics and work of breathing. In: Tobin MJ, ed. Principles and Practice of Mechanical Ventilation. New York, McGraw Hill, 1994; pp. 967-1003.

48. Bates JHT, Milic-Emili J. The flow interruption technique for measuring respiratory resistance. J Crit Care 1991; 6: 227-238.

49. Levy P, Similowski T, Corbeil C, et al. A method for studying the static volume-pressure curves of the respiratory system during mechanical ventilation. J Crit Care 1989; 4: 83-89.

50. Bernasconi M, Brandolese R, Poggi R, Manzin E, Rossi A. Dose-response effects and time-course of effects of inhaled fenoterol on respiratory mechanics and arterial oxygen tension in mechanically-ventilated patients with chronic airflow obstruction. Intensive Care Med 1990; 16: $108-114$.

51. Jackson AC, Milhorn HT Jr, Norman JR. A re-evaluation of the interrupter technique for airway resistance measurement. J Appl Physiol 1974; 36: 264-268.

52. Bates JHT, Rossi A, Milic-Emili J. Analysis of the behaviour of the respiratory system with constant inspiratory flow. J Appl Physiol 1985; 58: 1840-1848.

53. Rossi A, Gottfried SB, Higgs BD, Zocchi L, Grassino A, Milic-Emili J. Respiratory mechanics in mechanically-ventilated patients with respiratory failure. $J \mathrm{Appl}$ Physiol 1985; 58: 1849-1858.

54. Pepe PE, Marini JJ. Occult positive end-expiratory pressure in mechanically-ventilated patients with airflow obstruction. Am Rev Respir Dis 1982; 126: 166-170.

55. Hubmayr RD, Gay PC, Tayyab M. Respiratory system mechanics in ventilated patients: techniques and indications. Mayo Clin Proc 1987; 62: 358-368.

56. Gay PC, Rodarte JR, Tayyab M, Hubmayr RD. Evaluation of bronchodilator responsiveness in mechanicallyventilated patients. Am Rev Respir Dis 1987; 136: 880-885.

57. Marini JJ. Monitoring the mechanics of the respiratory system. In: Tobin MJ, ed. Respiratory Monitoring. Contemporary Management in Critical Care. Vol. 1. No. 4. New York, Churchill Livingstone, 1991; pp. 163-196.

58. Tuxen D, Lane S. The effects of ventilatory pattern on hyperinflation, airway pressures, and circulation in mechanical ventilation of patients with severe airflow obstruction. Am Rev Respir Dis 1987; 136: 872-879.

59. Leatherman JW, Ravenscraft SA, Iber C, Davies S. Does 
measured auto-PEEP accurately reflect the degree of dynamic hyperinflation during mechanical ventilation of status asthma? Am Rev Respir Dis 1993; 147: A877.

60. Breeden CC, Safirstein BH. Albuterol and spacer-induced atrial fibrillation. Chest 1990; 98: 762-763.

61. Higgins RM, Cookson WOCM, Lane DJ, John SM, McCarthy GL, McCarthy ST. Cardiac arrhythmias caused by nebulized beta-agonist therapy. Lancet 1987; ii: 863-864.

62. Dollery CT, Williams FM, Draffan GH, et al. Arterial blood levels of fluorocarbons in asthmatic patients. Clin Pharmacol Ther 1974; 15: 59-66.

63. Silverglade A. Cardiac toxicity of aerosol propellants. J Am Med Assoc 1972; 222: 827-829.

64. Kung M, Croley SW, Phillips BA. Systemic cardiovascular and metabolic effects associated with the inhalation of an increased dose of albuterol: influence of mouth rinsing and gargling. Chest 1987; 91: 382-387.

65. O'Callaghan C, Milner AD, Swarbrick A. Paradoxical bronchoconstriction in wheezing infants after nebulized preservative-free, iso-osmolar ipratropium bromide. $\mathrm{Br}$ Med J 1989; 299: 1433-1434.

66. Summer W, Elston R, Tharpe L, Nelson S, Haponik EF. Aerosol bronchodilator delivery methods: relative impact on pulmonary function and cost of respiratory care. Arch Intern Med 1989; 149: 618-623.

67. Bowton DL, Goldsmith WM, Haponik EF. Substitution of metered-dose inhalers for hand-held nebulizers: success and cost-savings in a large, acute-care hospital. Chest 1992; 101: 305-308.

68. Alvine GF, Rodgers P, Fitzsimmons KM, Ahrens RC. Disposable jet nebulizers: how reliable are they? Chest 1992; 101: 316-319.

69. Hamill RJ, Houston ED, Georghiu PR, et al. An outbreak of Burkholderia (formerly Pseudomonas) cepacia respiratory tract colonization and infection associated with nebulized albuterol therapy. Ann Intern Med 1995; 122: 762-766. 